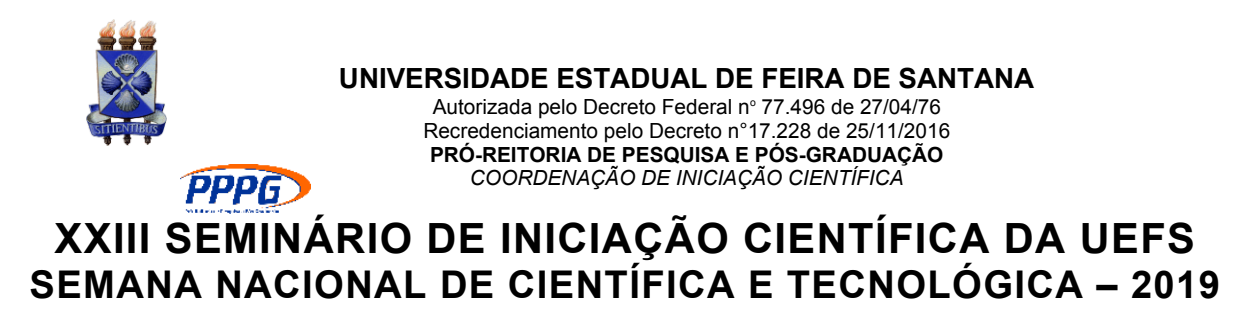

\title{
LÉXICO E CULTURA NO LIVRO SETEMBRO NA FEIRA
}

\author{
Thaise Leal de Souza ${ }^{1}$; Profa. Dra. Norma Lucia Fernandes de Almeida ${ }^{2}$ \\ 1. Bolsista PROBIC/UEFS, Graduanda em Letras com espanhol, Universidade Estadual de Feira de \\ Santana, e-mail: thaisyleal@hotmail.com \\ 2. Orientadora, Departamento de Letras e Artes, Universidade Estadual de Feira de Santana, e-mail: \\ norma.uefs@gmail.com
}

PALAVRAS-CHAVE: Léxico. Setembro na feira. Cultura.

\section{INTRODUÇÃO}

Inserida na área da Linguística, especificamente no estudo do léxico, a presente monografia apresenta uma investigação sobre a utilização do léxico recorrente no livro Setembro na Feira, do autor Juarez Bahia (1986). Averiguação essa, que identifiquei 17 lexias com marcas culturais encontradas na obra. Após a retirada dos dados foi realizada a análise dos significados das lexias identificadas, esses significados foram comparados com os significados encontrados em dicionários antigos e contemporâneos no sentido de verificar a manutenção ou não de significações mais antigas. Essa exploração se apoiou em estudos lexicográficos, tal como lexicológicos, propondo uma reflexão sobre a ligação entre língua, cultura e sociedade. A metodologia aqui utilizada se encontra sob os direcionamentos de uma pesquisa descritiva de base qualitativa. De tal leitura emergiram muitas marcas dos costumes que representam uma sociedade, o que se justifica devido à grande força cultural e às características explícitas de aspectos socioculturais, principalmente da cidade de Feira de Santana. Com efeito, ratifico que o léxico espelha a estrutura sócio-histórica de um povo e ilustra a sua cultura. Ainda, a realidade linguística é reflexo dos valores que são constituídos em um grupo social, e estes valores são diversos, mesmo entre os que compartilham da mesma língua. Assim, são apresentadas algumas relevâncias, das quais destaco: a conservação de uma carga histórica, social e cultural do sertão baiano, mais precisamente de Feira de Santana, podendo abarcar futuras pesquisas na área, de modo a contribuir para uma preservação literária não canônica.

\section{MATERIAL E MÉTODOS OU METODOLOGIA (ou equivalente)}

$\mathrm{Na}$ metodologia foi feito um estudo descritivo das ciências do léxico e da literatura, de natureza bibliográfica e com valor qualitativo, a pesquisa tem como corpus o romance Setembro na Feira (1986), do autor Juarez Bahia, sendo o corrente texto, dividido em seis seções: a primeira é a introdução, a segunda tem como título Vida e Obra de Juarez Bahia, a terceira Marco Teórico e Metodológico, posteriormente, segue a quarta seção denominada Análise do léxico culturalmente marcado em Setembro na Feira (1986), sucessivamente, na próxima seção, encontram-se as considerações finais. 


\section{RESULTADOS E/OU DISCUSSÃO (ou Análise e discussão dos resultados)}

Na pesquisa, foram identificadas 17 lexias contidas na obra Setembro na Feira (1986) - Juarez Bahia. Assim, se apresentam a seguir algumas das lexias encontradas:

CABOCLO (Origem Tupi/Indígena) - 1. S.m. (Bras.) Indígena brasileiro, de pele acobreada. 2. Mulato de cor acobreada, descendente de índios. 3. Mestiço de branco com índio (CALDAS, 1958, p.553).

1. S.m. Bras. Mestiço de branco com índio, cariboca, carijó. 2. Antiga denominação do indígena. 3. Caboclo de cor acobreada e cabelos lisos, caburé, tapuio. 4. Dançador do maracatu real (FERREIRA, 1999, p. 351).

APRESENTAÇÃO NO ROMANCE: “[...] Que houve? - perguntou logo. -Seu caboclo baixou. [...]" p. 228 / “[...] O quê, Nô? - O advento de caboclo Oxóssi [...]." p. 229

CANGACEIRO: (Origem Banto/Africana) - 1. S.m. (Bras.) Bandido, salteador, bandoleiro, jagunço (CALDAS, 1958, p.601).

1. S.m. Bras. Bandido do sertão nordestino, que andava sempre fortemente armado; assombra-pau, bandoleiro, cabra, cabra-de-chifre, capixaba, capuava (FERREIRA, 1999, p.389).

APRESENTAÇÃO NO ROMANCE: O maior cangaceiro do sertão baiano, vinte anos de mortes, assaltos, fugas, combates, perseguições, o fim na forca. Seu pai de criação, um padre; nascera de mãe escrava [...].” p.148

CANGAÇO (Origem Banto/Africana) - 1. Gênero de vida dos bandoleiros do Nordeste (cangaceiros); cangaceirismo (CALDAS, 1958. P.601).

1. O gênero de vida dos cangaceiros; cangaceirismo (FERREIRA, 1999, p.389).

APRESENTAÇÃO NO ROMANCE: “[...] Começa com ele o ciclo do cangaço nordestino. Vem ver, gente, a estória de Lucas da Feira. Os amores de Lucas, o porquê do limão. Dom Pedro Segundo não resistiu à tentação de conhecê-lo [...].” p. 148-149

CANJICA (Origem Banto/Africana) - 1. S.f. (Bras.) Espécie de sopa de milho branco, pilado; mungunzá (no Norte); jimbelê. 2. Papa de milho verde com açúcar, leite de coco e canela; curau (São Paulo e Mato Grosso); coral (Estado do Rio e Minas Gerais); canjiquinha (Rio de Janeiro) (CALDAS, 1958, p.604).

1. S.f. Bras. Papa de consistência cremosa feita com milho verde ralado, a que se acrescenta açúcar, leite de vaca ou de coco, e polvilha com canela. 2. Cural (São Paulo, Mato Grosso e Goiás). 3. Coral e papa de milho (Minas Gerais e Rio de Janeiro). 3. Canjiquinha (Rio de Janeiro) (FERREIRA, 1999, p.391).

APRESENTAÇÃO NO ROMANCE: “[...] Maria Pé-de-Revólver faz misturas alucinantes, a sua voz às manhãzinhas desperta as pessoas, com bom humor, com disposição para as iguarias de seu tabuleiro. Canjica, bolinhos de fubá e tapioca, tudo muito divertidamente apregoado pela vendedora [...]." p. 171

CANGALHA (Origem Banto/Africana) - 1. S.f. (Bras.) Triângulo de madeira que se enfia no pescoço dos porcos para que não entrem nas hortas cultivadas (CALDAS, 1958, p.601).

1. S.f. Bras. Peça de três paus, unidos em triângulo, que se enfia no pescoço dos porcos para não destruírem hortas cultivadas (FERREIRA, 1999, p.389).

APRESENTAÇÃO NO ROMANCE: “[...] São pobres como os pretos, tão pobres quanto os pretos e assim, embora brancos às vezes de olhos verdes, azuis, os que assim 
são também como pretos são tratados porque são pobres, chegam e saem, entram e saem da feira como anônimos, entram na cidade silenciosos, com seus objetos na cabeça, ou nos ombros, ou na carroça, ou na cangalha dos animais [...].” p. 158

CHIBUNGO: (Origem Banto/Africana) - Lexia não encontrada nos dicionários utilizados, porém é possível apreender a partir da leitura do trecho a seguir, que o autor utiliza esse termo para fazer referência ao sujeito homossexual.

APRESENTAÇÃO NO ROMANCE: “[...] O ódio - responde Seu Ia. Florêncio concorda, apertam-se as mãos. E Seu Ia, majestoso à frente das Melindrosas, impecável nos passos, senhor dos ritmos, cavalga o tempo, surdo às censuras aparentes, indiferente aos que, como Flô, um dia lhe chamam de chibungo, outro dia de preto, consciente e até envaidecido de suas inclinações femininas [...].” p. 36

JAGUNÇO: (Origem Banto/Africana) - 1. S.m. (Bras.) Valentão, guarda-costas de fazendeiro ou senhor de engenho, na Bahia. 2. O sertanejo nortista, ou mais incisivamente, o jagunço (CALDAS, 1958, p.2041).

1. S.m. Bras. Capanga (FERREIRA, 1999, p.1152).

APRESENTAÇÃO NO ROMANCE: “[...] Ancorado em seus jagunços, Heráclito mandava e desmandava - Rico sem ser aristocrata, teimoso, mas não arrogante, João Farinha só se aporrinha com os inimigos políticos e os galãs de suas amantes [...].” p. 43

MOQUECA (Origem Banto/Africana) - 1. S. f. (Bras.) Guisado de peixe ou de mariscos, temperados com coco, azeite e pimenta (CALDAS, 1958, p.2386).

1. Prato típico brasileiro, em geral de peixe ou de mariscos, podendo também ser feito de galinha, ovos, etc, e que consta de um guisado temperado com salsa, coentro, limão, cebola e sobretudo leite de coco, azeite-de-dendê e pimenta de cheiro (FERREIRA, 1999, p.1364).

APRESENTAÇÃO NO ROMANCE: “[...] Santinha mandara pedir uma receita especial de moqueca. Dê a ela, meu filho [...]." p. 155

PINGA: Não foi localizada a origem dessa lexia. - 1. S.f. Cachaça, aguardente (CALDAS, 1958, p.2817).

1. S.f. Bebida alcoólica, sobretudo aguardente (FERREIRA, 1999, p.1517).

APRESENTAÇÃO NO ROMANCE “[...] Da Queimadinha ao Mundo Novo, Morro do Chapéu, Lavras, São Francisco, por aí afora. Banana-maçã, carne-de-sol ao espeto, farofa de toucinho torresmo, pinga curada ao velame. Perto da natureza, mais rude que ela [...]." p. 67

SARARÁ: (Origem tupi/indígena) - 1. S.m. e $f$. (Bras.) aça ou mulato arruivado, albino (CALDAS, 1958, p.3294).

1. Que tem pêlos ruivos. 2. Albino. 3. Diz-se da cor alourada ou arruivada do cabelo muito crespo característico de certos mulatos (FERREIRA, 1999, p.1818).

APRESENTAÇÃO NO ROMANCE: “[...] Belmiro Bom Tempo, um sarará alto e forte, bem vestido, com jeito de doutor da cidade, queria falar ao comandante. Levar o protesto mais alto [...].” p. 67

VATAPÁ (Origem Banto/Africana) - 1.S.m. (Bras.) Papas de fubá de arroz ou de miolo de pão dormido, com azeite-de-dendê, pimenta, leite de coco, camarões secos, gengibre, castanhas de caju ou amendoim pisado e peixe ou carne de galinha (CALDAS, 1958, p.3759). 
1. S.m. Bras. Prato típico da cozinha baiana muito apimentado, feito com peixe ou galinha, a que se adiciona leite de coco, camarões secos e frescos, pão de véspera, amendoim e castanha de caju torrados e moídos, que se tempera com azeite-de-dendê, além dos temperos habituais (sal, cebola, pimentão, coentro, cheiro verde, etc.) (FERREIRA, 1999, p.2050).

APRESENTAÇÃO NO ROMANCE: “[...] Vatapá, feijoada, moqueca, sarapatel, maniçoba, malassado a escolher. Gente de cima e gente de baixo, pessoas que vêm de longe a matar o apetite [...]." p. 62

\section{CONSIDERAÇÕES FINAIS}

O presente estudo identificou e analisou 17 lexias marcadas culturalmente pela comunidade feirense, lexias essas que foram analisadas sob o título de 'marcas culturais' pelo fato de serem assim reconhecidas pelo senso comum, tal qual por serem ordinariamente utilizadas nos ambientes do Sertão, tanto quanto do Recôncavo Baiano. do total das lexias identificadas, 04 foram de origem Tupi/Indígena, 09 de origem Banto/Africana, 01 de origem Kwa/Africana e 03 de origens não identificadas. São elas: caboclo (Origem Tupi/Indígena), cangaceiro (Origem Banto/Africana), cangaço (Origem Banto/Africana), cangalha (Origem Banto/Africana), canjica (Origem Banto/Africana), caruru (Origem Banto/Africana), chibungo ou xibungo (Origem Banto/Africana), jagunços (Origem Banto/Africana), maniçoba (Origem Tupi/Indígena), moqueca (Origem Banto/Africana), mocotó (Origem Tupi/Indígena), Oxum (Origem Kwa/Africana), pau de sebo (Origem não identificada), pinga (Origem não identificada), sarapatel (Origem não identificada), sarará (Origem Tupi/Indígena), vatapá (Origem Banto/Africana). Sendo assim, dessas lexias, a maioria foi de origem Africana, mais especificamente, Banto/Africana, dado que vai de encontro ao que a professora Yeda Pessoa de Castro disse em entrevista realizada por Scarrone (2015), onde, segundo a autora, "a proximidade entre o português arcaico e as línguas do grupo banto resultou no português que falamos hoje".

A África está imersa no Brasil em tudo, principalmente na Bahia. De acordo com Santos, a cidade de Cachoeira, na Bahia, é detentora de um considerável acervo cultural do Brasil. (SANTOS, 2007, p. 12). Já no que tange ao bairro Queimadinha, a identidade do local, ambiente onde vivia Juarez Bahia, também está vinculada à valores culturais de origem africana. Clóvis Ramaiana Oliveira identificou em sua tese de doutorado, que os bairros de classe baixa do município de Feira de Santana, eram ocupados, na sua maioria, por negros. O historiador utilizou os termos "Negros subúrbios" para se referir à cor das pessoas dessas regiões, dentre esses locais encontrase o bairro Queimadinha. Essa afinidade do autor Juarez Bahia com a cultura do povo negro justifica o fato de a maioria das lexias utilizadas por ele terem sido de origem africana. Por este ângulo, é possível atestar que esse contato direto do autor Juarez Bahia com a cultura do povo negro justifica o fato de a maioria das lexias identificadas terem sido de origem africana. Assim sendo, se faz importante ressaltar que a cultura do continente africano é parte constitutiva da história e da memória brasileira, particularmente da memória do município aqui estudado, e seu entendimento vai muito além das margens desse texto.

Por fim, a pesquisa aqui apresentada tinha como objetivo identificar e analisar as lexias que marcam a cultura feirense, contidas na obra Setembro na Feira (1986), com isso, o objetivo foi cumprido. Espera-se que este estudo possa incentivar outras pesquisas sobre o tema aqui proposto, da mesma maneira que a pesquisadora que aqui vos fala, foi incentivada através de outras pesquisas na área. 


\section{REFERÊNCIAS}

BAHIA, J. Setembro na feira. Romance. Rio de Janeiro: Nova Fronteira, 1986.

CALDAS A., F. J.; GARCIA, H.; NASCENTES, A. Dicionário contemporâneo da língua portuguesa. Rio de Janeiro: Delta, 1958.

FERREIRA, A. B. H. Novo Aurélio século XXI: o dicionário da língua portuguesa. 3. ed. Rio de Janeiro: Nova Fronteira, 1999.

CASTRO, Y. P. de. Falares africanos na Bahia: um vocabulário afro-brasileiro. 2. ed. Rio de Janeiro: Academia Brasileira de Letras e Topbooks, 2005.

CASTRO, Y. P. de. Nossa língua africana. Portal Vermelho: 16 jun. 2015. Entrevista concedida a Marcelo Scarrone. Disponível em: http://www.vermelho.org.br/noticia/265993-11. Acesso em: 10 ago. 2019.

FERREIRA, A. B. H. Novo Aurélio século XXI: o dicionário da língua portuguesa. 3. ed. Rio de Janeiro: Nova Fronteira, 1999.

OLIVEIRA, C. F. R. M. Canções da cidade amanhecente: urbanização, memórias urbanas e silenciamentos em Feira de Santana, 1920-1960. 2011. 257f. Tese (Doutorado em História) - Programa de Pós-Graduação em História, Universidade de Brasília, Brasília, 2011. Disponível em: http://repositorio.unb.br/bitstream/10482/10624/3/2011_ClovisFredericoRamaianaMora esOliveira.pdf. Acesso em: 12 ago. 2019.

TRUJILLO, A. M.; TRUJILLO, M. F. F. Estudo diacrônico de mudanças semânticas em preposições na língua portuguesa. Travessias, v. 10, n. 3, p. 159-172. Disponível em: http://e-revista.unioeste.br/index.php/travessias/article/view/14692. Acesso em: 17 jul. 2019. 